\title{
Sounding Pico
}

\author{
Maj Hasager \\ Henrik Rungs Gade 5, 2. tv \\ 2200 Copenhagen N \\ Denmark \\ majhasager@gmail.com
}

\author{
Ask Kæreby \\ Royal Academy of Music \\ Musikkens Plads 1 \\ 9000 Aalborg \\ Denmark \\ mail@askkaereby.net
}

\begin{abstract}
Sounding Pico is an art project focussing on the Pico-neighbourhood in Santa Monica, CA in the USA developed in collaboration between artist Maj Hasager and composer Ask Kæreby during winter 2018-19. In response to the often-mediated image of a troubled area with opportunities lost, rather than gained, countermeasures have been taken - perhaps most notably by the cultural asset database Culture Mapping 90404, initiated by $18^{\text {th }}$ Street Arts Center. In an attempt to supplement with the perspectives of younger generations, we invited a number of young, local residents and musicians to record characteristic sounds of the area, which were later interpreted on their acoustic instruments and made available online as part of a soundwalk. By bringing forward these young musicians as local resources, as well as their ear for local soundmarks, we aim to shine a different light on the area, and to supplement and further the debate around it.
\end{abstract}

Santa Monica. Pico. Soundwalk. Soundscape. Performance. Art. Participatory.

\section{INTRODUCTION}

In this short paper we present Sounding Pico - a work of art made in collaboration between a visual artist (Maj Hasager) and an electronic composer (Ask Kæreby). A key element of the work is the inclusion of a soundwalk, with which we also attempted to challenge the dominant perception of the concept: 'an elaborated, listening-oriented, modern variety of an traditional walk [...] assumed to lead to a heightened awareness and an ecological attitude' (Staśko-Mazur, 2015). The concept of the soundwalk has largely been defined by Canadian composer and founder of the discipline Acoustic Ecology R. Murray Schafer, but although our approach can be said to have a sort of 'score as a guide' (Schafer, 1977, pp. 212-13), our view on natural and man-made sound lies closer to that of American percussionist and artist Max Neuhaus, whose 'listening walks' predates Schafer's soundwalks, and who argued against an indiscriminate battle on urban sounds, stating that 'silencing our public environment is the acoustic equivalent of painting it black' (Murph, n.d.).

Sounding $P$ ico is a work focussing on the Piconeighbourhood in the city of Santa Monica, which is located on the Californian west coast of the USA. We developed it in collaboration during a 6-month stay in the area in winter 2018-19, while Maj Hasager was artist in residence at 18st Street Arts Center, courtesy of the Danish Arts Foundation.
We've collaborated on a few projects previously, a recent example being The dissonance of m emory which revolved around Gellerupparken's history, a so-called Ghetto outside the city of Aarhus in Denmark. The project focussed on personal memories and their significance for historical writing about a place. Hasager produced a film and a series of works, which Kaereby supplemented with a composition of abstract audio objects from manipulated field recordings made in the area, which was performed as live sound diffusion during SPOR Festival 2018.

The Pico neighbourhood in Santa Monica used to be much larger and was an important AfricanAmerican enclave on the Westside of LA, but when the Santa Monica Freeway opened in the 1960s, it resulted in the destruction of many residences and the relocation of a large number of families (Rubin, 2017). It is the most ethnically diverse area of Santa Monica, but this diversity is under threat as the area is rapidly becoming gentrified. The Pico neighbourhood has higher crime rates than the rest of the city, and The City of Santa Monica has been accused of ignoring the Pico District in the past, particularly when it came to issues regarding crime and gang activity.

Located in Pico area, $18^{\text {th }}$ Street Arts Center has a mission statement, which is 'to provoke public dialogue through contemporary art-making' and has a long history as a space for artists. Originally a studio space for a group of feminist artists in the 
1970s -80 s, $18^{\text {th }}$ Street Arts Center today walks on two legs, so to speak: a Residency Program that fosters inter-cultural collaboration and dialogue and a Public Events and Exhibition Program that focuses on engaging the public ('About,' n.d.).

\section{SUPPLEMENTING CULTURAL MAPPING}

In response to the often-mediated image of the Pico neighbourhood as a troubled area with opportunities lost, rather than gained, countermeasures have been taken. One notable example is the cultural asset database Culture Mapping 90404, initiated by $18^{\text {th }}$ Street Arts Center, which catalogues 'places that define the culture of the neighbourhood, according to the people who live here' ('Main Culture Mapping 90404,' n.d.). This effort was a major reason for Hasager's stay, during which she met with dozens of people in the community, using the map as a jumping off point to orient herself to local history - but also as a way to identify gaps in the narrative.

One of the people she met was Shabnam Fasa, an Iranian-American who grew up in Denmark, and who had founded Santa Monica Youth Orchestra, a tuition-free orchestra and choir for young people ages 6-16 at Virginia Avenue Park, which offers high quality music programming for more than 150 students ('About | Santa Monica Youth Orchestra,' n.d.). She encouraged us to involve the orchestra, and we decided to do so, in an attempt to supplement the cultural mapping with the perspectives of younger generations, whose involvement in these matters had been limited. The database features many entries primarily relating to older generations, and the method of documentation is mostly videos of interviews. We wanted to supplement this with a different medium, and the perspective of a young, local person. As Santa Monica Youth Orchestra was strangely not even on the map of the Mapping 90404 project, we invited these young, local residents and musicians to go out and record characteristic sounds of the area, during one of their Sunday rehearsals. Afterwards we asked them to study their recordings at home and interpret them on their acoustic instruments, which we then recorded. To us, the instrumental versions of the environmental sounds were even more interesting than the field recordings - the translation to instrumental sound by young musicians using their ears, minds and body, added further layers of sonic hints as to how they listen and what they found interesting. A total of 27 corresponding instrumental sounds and field recordings were made available online as part of a soundwalk on 3 March 2019 ('SMYO soundwalk,' n.d.), which had signs throughout the park linking the recorded sounds to that particular spot, and a simple map to help locate them.
One of the better-known exponents for the merits of the soundwalk is the composer Hildegard Westerkamp (Westerkamp, 2006), who took part in The World Soundscape Project, established by composer Murray Schafer at Simon Fraser University in Canada during the late 1960s/early 1970s ('WORLD SOUNDSCAPE PROJECT,' n.d.). In the acoustic ecology tradition founded by Schafer, soundwalks have been used as a method for cultivating an interest in the sonic environment, more often than not with the appreciation of the 'unspoilt' sounds of nature as its focal point (Schafer, 1977, pp. 205-213). While it became apparent that the wind and the rain are still good sources of sound for a smartphone-equipped young generation of musicians, we were pleased to learn that the sounds of impact on metal or concrete surfaces, squeaky playground equipment and electric vehicles were amongst the recordings made by the participants. This was in line with our (and Neuhaus') belief that a soundwalk (and a soundscape composition) doesn't have to lead to a celebration of the pastoral.

\section{RELATING TO THE SITE}

In Maj Hasager's socially engaged practice, she is very interested in a dialogical approach to the participatory and often large-scale workshops that she develops as part of her artistic projects. In the series of workshops we did with Santa Monica Youth Orchestra, a central matter was shifting the perspective from skill-based learning situation to an interpretive engagement with a site and their instruments. Specifically, how the engagement with the exterior could inform the young participants' thinking and their approach to their instruments, as well as creating space for reflection on their local surroundings, which often seem to go unnoticed. The soundwalk presented on 3. March 2019 was a way of engaging an extended community (a general audience of park visitors as well as friends and relatives of the musicians) in listening to their surroundings from the perspectives of young minds. The soundwalk was installed in Virginia Avenue Park in the center of the Pico Neighbourhood where the sounds had been collected. With its hyperlocal focus, a space for listening and a presentation of a participatory project, the site became a place for dialogue - and, for the children, an active way of connecting back to a place they spend most Sundays when rehearsing for the symphonic orchestra, but perhaps without thinking too much about the site itself.

A performance by Santa Monica Youth Orchestra served as the opening event for the soundwalk. Based on the instrumental interpretations of the field recordings, we had the orchestra play a partly improvised concert of sounds of - and in - the 


\section{Sounding Pico \\ Maj Hasager • Ask Kæreby}

environment. This was done with great help from conductor Rachel Iba and the Santa Monica Youth Orchestra staff, and it was the first time the orchestra had performed outdoors, in the park.

Wanting to expand the dialogue between soundscape, artist and composer, we involved locals in what art historian Claire Bishop refers to as the primary audience (Bishop, 2012, p. 149). In this way it can be said that the project functions in the realm of a participatory practice where works have shared authorship, as famously described by Roland Barthes. While Hildegard Westerkamp has described a more traditional process in which the inherent meaning of a recorded soundscape becomes apparent to the composer after repeated listening and processing (Westerkamp, 2002) - we were interested in expanding this sphere of meaning with the use of 'local ears' to help identify and collect sounds. Not because someone has to do the work for us, but because we are interested in how a given place is heard, filtered and contextualized through the listening of local people, with the experiences and attitudes that subconsciously and consciously characterize their perception.

We noticed some tension within some of the young musicians, when prompted to handle their instruments 'inappropriately' or to produce sounds that were unwanted in a classical symphonic setting (which some confided to us during recording), and many seemed excited about the use of smartphones - normally banned during rehearsal - for recording environmental sounds. Throughout the day of the performance and soundwalk, they all seemed to interact differently and more intensely with the surroundings (not only with the sites that linked to recorded and interpreted sounds) and the event served as an introduction for an expanded audience - not only to Santa Monica Youth Orchestra, but also to its sonic environment. The event also had significance for the orchestra's existing audience one member of the audience told us how having the orchestra outside for the event had suddenly brought attention to the surroundings and forged links between the interior and exterior, noting how art has a potential to make connections like these.

\section{REFERENCES}

About, n.d. 18th Str. Arts Cent. URL https://18thstreet.org/about/ (accessed 9.12.19).

About | Santa Monica Youth Orchestra [WWW Document], n.d. URL https://www.santamonicayouthorchestra.org/abo ut (accessed 9.12.19).

Bishop, C., 2012. Artificial hells: participatory art and the politics of spectatorship. Verso Books, London: New York.
Main - Culture Mapping 90404 [WWW Document], n.d. URL http://culturemapping90404.org/ (accessed 9.12.19).

Murph, M., n.d. Max Neuhaus's Sound Works and the Politics of Noise. Ecomusicology Rev. URL https://ecomusicology.info/max-neuhausssoundworks-and-the-politics-of-noise/

(accessed 12.8.19).

Rubin, S., 2017. Mapping the Culture of Santa Monica's Pico Neighborhood. St. Monica Next. URL

http://www.santamonicanext.org/2017/04/mappin $\mathrm{g}$-the-culture-of-santa-monicas-piconeighborhood/ (accessed 9.12.19).

Schafer, R.M., 1977. The Tuning of the World, 1st edition. ed. Random House Inc, New York.

SMYO soundwalk [WWW Document], n.d. SoundCloud. URL https://soundcloud.com/askkaereby/sets/smyosoundwalk (accessed 9.12.19).

Staśko-Mazur, K., 2015. Soundwalk as a multifaceted practice. Argument 2/2015, 439455.

Westerkamp, H., 2006. Soundwalking as Ecological Practice, in: Proceedings for the International Conference on Acoustic Ecology. Presented at the The West Meets the East in Acoustic Ecology, Hirosaki University,Hirosaki, Japan.

Westerkamp, H., 2002. Linking soundscape composition and acoustic ecology. Organised Sound 7, 51-56. URL https://doi.org/10.1017/S1355771802001085

WORLD SOUNDSCAPE PROJECT [WWW Document], n.d. URL

https://www.sfu.ca/ -truax/wsp.html (accessed 1.12.19). 